\title{
Using Rich Narratives to Engage Students in Worthwhile Mathematics: Children's Literature, Movies and Short Films
}

\author{
James Russo ${ }^{1, * \mathbb{D}}$, Toby Russo ${ }^{2}$ and Anne Roche ${ }^{1}$ \\ 1 Faculty of Education, Monash University, Clayton, VIC 3800, Australia; anne.roche@monash.edu \\ 2 Spensley Street Primary School, Clifton Hill, VIC 3068, Australia; Toby.Russo@education.vic.gov.au \\ * Correspondence: james.russo@monash.edu
}

Citation: Russo, J.; Russo, T.; Roche, A. Using Rich Narratives to Engage Students in Worthwhile Mathematics: Children's Literature, Movies and Short Films. Educ. Sci. 2021, 11, 588 https://doi.org/10.3390/ educsci11100588

Academic Editors: Eila Jeronen and Liudmila Liutsko

Received: 20 August 2021

Accepted: 23 September 2021

Published: 27 September 2021

Publisher's Note: MDPI stays neutral with regard to jurisdictional claims in published maps and institutional affiliations.

Copyright: (c) 2021 by the authors. Licensee MDPI, Basel, Switzerland. This article is an open access article distributed under the terms and conditions of the Creative Commons Attribution (CC BY) license (https:/ / creativecommons.org/licenses/by/ $4.0 /)$.

\begin{abstract}
Using children's literature to support mathematics instruction has been connected to positive academic outcomes and learning dispositions; however, less is known about the use of audiovisual based narrative mediums to support student mathematical learning experiences. The current exploratory, qualitative study involved teaching three lessons based on challenging, problem solving tasks to two classes of Australian Year (Grade) 5 students (10 and 11 year olds). These tasks were developed from various narratives, each portrayed through a different medium (movie clip, short film, picture story book). Post lesson interviews were undertaken with 24 students inviting them to compare and contrast this lesson sequence with their usual mathematics instruction. Drawing on a self-determination theory lens, our analysis revealed that these lessons were experienced by students as both highly enjoyable and mathematically challenging. More specifically, it was found that presenting mathematics tasks based on rich and familiar contexts and providing meaningful choices about how to approach their mathematical work supported student autonomy. In addition, there was evidence that the narrative presentation supported student understanding of the mathematics through making the tasks clearer and more accessible, whilst the audiovisual mediums (movie clip, short film) in particular provided a dynamic representation of key mathematical ideas (e.g., transformation and scale). Students indicated an eclectic range of preferences in terms of their preferred narrative mediums for exploring mathematical ideas. Our findings support the conclusion that educators and researchers focused on the benefits of teaching mathematics through picture story books consider extending their definition of narrative to encompass other mediums, such as movie clips and short films.
\end{abstract}

Keywords: mathematics education; narratives; self-determination theory; problem solving; challenging tasks; children's literature; audiovisual media; elementary education

\section{Introduction}

For many years researchers and policy makers have endeavored to describe the kinds of pedagogical practices that contribute to improved student outcomes in mathematics [1-3]. Common to these lists of practices is the importance of mathematical tasks and the features of tasks considered to promote learning. Indeed, the quality of tasks that students engage with in the classroom has been acknowledged as key to "how students come to view, develop, use and make sense of mathematics" [1] (p. 13). Following a review of the values and practices considered to be the most important and effective by the mathematics education community, Swan [3] outlined eleven principles for teaching mathematics based in research. One focused solely on tasks. It stated, "Teaching is more effective when it uses rich, collaborative tasks which promote mathematics learning, are accessible, extendable, encourage decision making, promote discussion, encourage creativity, encourage 'what if' and 'what if not' questions" (p. 4). NCTM [2] recommended that students should be exposed to worthwhile and meaningful mathematical tasks, that promote problem solving and reasoning, and develop students' dispositions for learning mathematics. They 
suggested that such tasks often have more than one solution strategy, can be represented in multiple ways and demand students justify and communicate their understandings.

Some studies have investigated the use of challenging tasks or tasks with a high cognitive demand [4-6]. They have been shown to promote productive struggle, which is important for learning mathematics with understanding [7]. Sullivan and Mornane [5] investigated the use of challenging tasks that encourage persistence. They believed that it was possible for everyone to learn mathematics but that it takes concentration and effort over a sustained period of time. The results of their study indicated that the students learned the content and that some students' revealed a preference for these types of tasks. Other studies have similarly reported that primary students can embrace challenging tasks, thrive on the struggle, and that many students reported that working on these tasks was interesting and enjoyable $[6,8,9]$. We note that such studies involving challenging tasks generally incorporated a problem solving approach. Such an approach to teaching mathematics:

$[U]$ ses interesting and well-selected problems to launch mathematical lessons and engage students. In this way, new ideas, techniques, and mathematical relationships emerge and become the focus of discussion. Good problems can inspire important mathematical ideas, nurture persistence, and reinforce the need to understand and use various strategies, mathematical properties, and relationships [2] (p. 182).

Moreover, some studies have specifically focused on the effect of a problem solving approach for teaching mathematics $[10,11]$. These studies reported that students had positive attitudes about learning mathematics through problem solving even when the tasks were challenging and that this approach was shown to support their mathematical learning. These findings resonated with Cai [12] who summarized earlier research on teaching mathematics through problem solving. He reported that "students who had experienced problem-based instruction showed significantly more growth in mathematical reasoning, communication, making connections, and problem solving than did students receiving traditional instruction" (p. 251).

One type of problem solving task are those that are contextualized [13]. Relevant to the current study is the use of tasks that are embedded in a context. Mathematical problems with a context have been given various names such as contextualized tasks [13], real-life problems [14] and modelling activities [15] to name a few. These have been differentiated from word problems which are contextualized "in a more contrived manner" [15] (p. 22).

Borasi [14] defined the context as "the situation in which the problem is embedded" (p. 129). Clarke and Roche [13] described the mathematical focus as the starting point for a contextualized task and the context as exemplifying this. Meyer and colleagues [16] suggested that the context in mathematics curricula have five roles, namely to: 1 . Motivate students; 2 . Offer opportunities to apply mathematics; 3 . Serve as a source of new mathematics; 4. Suggest a possible solution strategy; and 5. Provide an anchor for mathematics understanding. In terms of motivating students, Clarke and Roche [13] reported on the preferences of 11-15-year-old students for three task types: contextualized tasks, open ended tasks, and tasks with purposeful representations. Overall, there was a range of preferences for which they enjoyed the most, felt were the easiest and from which they learned the most.

The focus of the current research is on the use of challenging tasks that begin with a narrative [17] to support students in upper primary school (Year 5; 10 and 11 year olds) to explore proportional reasoning. Proportional reasoning refers to the capacity to compare situations in relative (multiplicative) rather than absolute (additive) terms [18]. It has been described as the capstone of primary mathematics and the cornerstone of secondary mathematics [19]. Tasks involving proportional reasoning were chosen for this study because, despite its importance and evidence that students often struggle in this domain [20], lessons focused on this topic are often procedural in nature and "do not engage students in analyzing, comparing, evaluating arguments, or similar thinking practices" (p. 258) [21]. By contrast, teaching proportional reasoning through challenging, 
problem solving tasks, such as those developed for the current study, is more likely to engage students' critical faculties.

The narratives were initiated from a movie clip, a short film, and a picture story book and provided the context for the associated mathematical task. Given the importance of mathematical tasks and problem solving for supporting student mathematical learning and associated dispositions, we aimed to investigate whether tasks that emerged authentically from a familiar narrative would produce a more positive student learning experience, compared with a typical mathematics lesson. The research questions driving the study were:

1. How does learning mathematics through challenging tasks embedded in narrative contexts shape the student learning experience, when compared with a typical mathematics lesson?

2. When learning mathematics through narrative contexts, to what extent do students demonstrate a preference for learning mathematics through a particular medium (movie clip, short film, or picture story book)?

In the next section we define narratives and outline the background literature associated with the use and benefits of picture story books and audiovisual media in mathematics lessons.

\subsection{Narratives}

Bruner [22] argued that narratives "operate as an instrument of the mind in the construction of reality" (p. 6). Scholes [23] defined narrative as "the symbolic presentation of a sequence of events connected by subject matter and related by time. Without temporal relation we have only a list" (p. 205). He argued that a story is a special kind of narrative "with a certain very specific syntactic shape (beginning-middle-end or situationtransformation-situation) and with a subject matter which allows for or encourages the projection of human values upon the material" (p. 206). The use of narratives has the potential to make the mathematics more realistic and relatable. Chao and colleagues [24] suggested "a narrative structure might facilitate students' identification with a figure, if the narrative is one to which students can relate" (p. 270).

Further, the term narrative has been used to describe a way of thinking in mathematics. Sinclair and colleagues [25] differentiated between two modes of thinking in mathematics (narrative and paradigmatic) and suggested they have complementary roles in the construction and organization of knowledge:

The paradigmatic is concerned with what is, given the constraints of the system in question, and with identifying and proving generalities that characterize objects and relations in the system, the narrative focuses on particular activities of these objects as they are played out in time, on what might be behind the events in question and on how they resemble or remind us of other things we know about ( $p$. 443).

In a broader educational context, Colucci-Gray et al. [26] highlighted the importance of arts being at the heart of an integrated education, which encompasses the notion of narrative or storytelling. They described the origins of STEAM (Science, Technology, Engineering, Arts and Mathematics) as a means of developing innovation, creativity, motivation, and inclusion. Storytelling was one pedagogical activity for building connections between subjects and enhancing motivation and inclusion.

We argue that beginning a mathematics lesson with a narrative and subsequently investigating a mathematical problem that emerges authentically from the story provides students with an opportunity to move beyond the relations in the mathematics system. It is an invitation to adopt a mathematical lens to consider the how and why behind the events in the story, and ultimately supports students to build a deeper conceptual understanding of the mathematical content being explored. Furthermore, we prioritize the text over the curriculum and argue that the narrative is chosen first (a story book or short media clip) and a rich problem solving task is developed that connects to some key component of 
the narrative. The curriculum links arise retrospectively. We call this the narrative-first approach [17]. It aligns with Trakulphadetkrai and colleagues' [27] second category of mathematical stories, which refers to narratives which were "not originally created with an intention for them to become a mathematical story but containing a storyline that lends itself naturally for a mathematical investigation" (p. 202). The benefits of using narratives (children's literature and audiovisual media) in mathematics lessons are now discussed.

\subsection{Using Children's Literature in Mathematics Instruction}

The use of children's literature or picture story books in mathematics instruction is a commonly promoted practice with a rich history over decades [28]. A recent study by Livy and colleagues [29] revealed that three-quarters of Australian in-service primary school teachers who responded to their questionnaire used children's literature to support mathematics instruction at least occasionally, with around one-third of study teachers doing so more frequently (at least once per month). Numerous books describe the ways in which stories can be used as a springboard or hook for exploring mathematical ideas [30,31]. Additionally, there is a plethora of articles that describe experiences in the classroom where mathematics is taught beginning with a story considered high-quality literature and engaging for the relevant grade level [32-35].

Although many of these articles are not based on empirical research, they nevertheless espouse the potential benefits of teaching mathematics through children's literature. They often explain that using story books to create rich learning experiences can promote enjoyment in learning, engage and motivate students to learn mathematics, and ultimately foster positive mathematical dispositions. Furthermore, the contexts of the stories can connect the mathematics to students' lives and interests, therefore making the mathematics meaningful and relevant. For example, Usnick and McCarthy [36] argued that adolescents could be motivated to learn mathematics through literature that is a springboard for explorations that integrate the curriculum. Furner [37] also described potential benefits for older students, concluding that using literature in the teaching of mathematics had the potential for increasing students' interest (and reducing anxiety) in STEM related subjects.

As well as benefits in the affective domain, others have described the potential benefits for students academically. Edelman and colleagues [38] reported on a systematic review of 23 studies on children's literature and mathematics teaching and learning during a twentyfive-year period (1991-2016). Participants included children between the ages of 18 months and 14 years, parents of children of that age range or teachers. Initially the review's search for relevant articles determined that there were many publications on this topic; however, far fewer were based on empirical research. Overall findings from those reporting on empirical research indicated that the use of children's literature for teaching mathematics had a positive impact on student achievement outcomes and mathematical discourse. The findings also concluded that students' engagement and interest in mathematics may increase with the use of children's literature; however, motivation and engagement were measured the least amongst the studies considered.

Much of the empirical research exploring the benefits of using children's literature has typically focused on preschool or early primary children (e.g., [39-43]). However, Capraro and Capraro [44] found that the use of children's literature to teach geometry in a sixthgrade classroom demonstrated that the students in the experimental group outperformed the non-story group on geometry ability when controlling for pretest performance. The current study contributes empirically towards understanding upper primary students ${ }^{\prime}$ beliefs about the ways in which using a story to initiate a mathematics task motivates them to engage in a complex mathematics topic.

\subsection{Using Audiovisual Media in Mathematics Instruction}

Despite the plethora of articles on children's literature, much is less is known about the impact of using a short movie or film clip to initiate a mathematics lesson. However, we would suggest that many of the benefits reported for the use of children's literature 
would be similar for audiovisual media. Indeed, Martinovic and colleagues [45] argued that because of its pervasiveness in recent decades the use of digital media can have a profound impact on young people's mathematics learning. They concluded that:

active participation in virtual mathematical opportunities may help not only to preserve students' natural motivation and the interest they have in the world around them, but also turn such interest into meaningful mathematics learning, full of opportunities for enrichment and collaboration, and thus supporting the emergence of a new learning culture (p. 233).

However, the authors also indicated that further research is required to understand the cognitive, affective, and social outcomes of its use.

Prior research has examined the use of video on students' interest or potential interest in mathematics content. Pierce and colleagues [46] advocated for movies that "offer an excellent way of bringing real world situations into the mathematics classroom" (p. 26). They outlined a project (Real world problems and information technology enhancing mathematics - RITEMATHS) in which digital images and movies are created by students or for students by the teachers to teach secondary mathematics content. The authors outlined some of the educational benefits. These were, "to bring real world problems alive in the classroom, to personalize mathematics, thereby increasing engagement of students, to integrate mathematics with many other subjects, and to make good use of information technology and students' interest in it" (p. 26). These benefits were not dissimilar to those described for the use of children's literature. Chao and colleagues [24] examined the impact of three digital resources (computer games, interactive lessons, and on-line videos) on fifth to eighth grade students' motivation and self-efficacy for learning mathematics. The online video was a commercially produced 55-min video about fractals with appealing animations and interviews with mathematicians. There were no follow up activities focusing on fractals. The findings revealed that around half of the group found the video interesting or enjoyable, and the authors concluded that the content (fractals) may have been the factor precluding some from enjoying the video.

It is notable that neither Pierce and colleagues' [46] nor Chao and colleagues' [24] studies examined the ways in which the students engaged with the mathematics following the viewing of the videos. Moreover, these studies described a substantially different approach for using audiovisual media compared with the current study, which used a narrative-based video as a hook into a mathematical investigation. Consequently, the current study contributes to the literature gap about the use of audiovisual media to provoke rich investigations and interest in mathematics.

\subsection{Engagement and Interest}

The construct of student engagement is multidimensional and complex [47]. It is necessary for learning, develops over time and can be facilitated by experiences in the classroom environment, as well as within the students themselves [48,49]. Furthermore, students' interest and engagement with classroom activities are positively related to academic achievement [50-52] and increased interest can lead to increased motivation to learn [53]. Ainley [54] identified the importance of the classroom task for developing students' interest and engagement. She reported that "students' initial reaction to the task sets a direction for their level of engagement" (p. 293). However, the relationship between task, interest and engagement is complex. Renninger [52] explained that "interest does not reside solely in the tasks or in the person but in the possibilities for activity that are perceived by the individual" (p. 396). For this reason, it is important to investigate students' perceptions of their experience when working on a mathematical task. Indeed, Middleton [55] argued that because much of students' motivation in mathematics is due to the nature of tasks and other classroom features, "careful attention to the redesign of these factors may afford the development of situational interest in students-thus engendering more excitement, on task behaviors, and subsequent mathematical learning" (p. 78). However, little is known about why tasks might produce enjoyment or interest in some students more than others. 
To this end, Schukajlow and Krug [56] investigated students' experiences of autonomy, competence, and interest when engaged with mathematics problems that were challenging, based on real world situations, and had multiple solutions and multiple pathways to solutions. They reported that students' prior interest influenced their experiences of autonomy and competence, and their interest increased the more they felt autonomous and competent. Therefore, experiences that facilitated feelings of autonomy and competence contributed to an increase in interest and overall enjoyment. As will be discussed, autonomy, competence and relatedness are three basic psychological needs [57] that contribute to a students' interest and motivation to learn.

\subsection{Theoretical Framework: Self-Determination Theory}

Self-determination theory is put forward as a framework for understanding why we anticipate students will enjoy learning mathematics through exploring problem solving tasks grounded in rich, familiar narratives. Exponents of self-determination theory contend that there are three primary psychological needs that motivate people's behavior: autonomy, competence and relatedness. It is suggested that meeting these needs is critical for psychological functioning and wellbeing [58]. Autonomy describes "the need to self-regulate one's experiences and actions", and is "associated with feeling volitional, congruent and integrated" [59] (p. 10). Competence refers to "our basic need to feel effectance and mastery", particularly within contexts that are valued by the individual [59] (p. 11). Finally, relatedness involves a general sense of "feeling socially connected" (p. 11). The relevance of each of these three psychological needs in an educational context, and how they are anticipated to be supported by a narrative-driven, problem solving approach to teaching mathematics, is outlined below.

\subsubsection{Autonomy}

Much has been written about self-determination theory in the context of understanding how students interact with their learning environment [60]. Importantly, through the lens of self-determination theory, high quality engagement and a sense of autonomy need not be contingent on an individual being intrinsically motivated to undertake a particular task or activity; but rather can be experienced through internalizing one's extrinsic motivations. In particular, identified regulation involves perceiving a particular activity as valued or important, and integrated regulation involves perceiving a particular activity as connected to one's authentic self $[60,61]$. In both these instances, even though the individual is externally motivated in the sense that they are seeking an outcome that can be separated from engaging in the activity itself [62], they experience high quality engagement, positive emotions and relative autonomy [60]. The implication is that autonomy can be cultivated in learning environments through both providing students with choice and designing learning activities that are perceived by students as purposeful and that resonate with who they are as young people.

In the context of the current study, it is postulated that learning mathematics through tasks that emerge authentically from rich narratives will lead to students experiencing autonomy. First, autonomy will be supported by working on problem solving tasks that have multiple possible solutions and/or can be feasibly solved in multiple possible ways $[8,63]$. Second, the rich contexts in which the tasks are embedded, that both connect to and validate children's imaginative worlds, will lead to the mathematics being perceived as relatively purposeful and valued.

\subsubsection{Competence}

Competence relates to the psychological need to be effective when interacting with a given context, in order to be in a position to obtain valued outcomes [64,65]. It is connected with opportunities to demonstrate that one can successfully navigate the demands of one's learning environment, and the feelings of efficacy resulting from this successful navigation [57]. Within a learning context in which student autonomy is supported through the 
affordance of choices that are relevant to a student's world, a student's need for competence is supported through ensuring that these choices represent "sufficiently complex options" [60] (p. 259).

Within our study, we contend that considering mathematical tasks that are embedded within rich narratives will promote student competence through improving their grasp of the mathematical ideas in focus. We suggest that this will occur through at least two means that have been previously shown to be connected to mathematical competence and understanding:

- Encouraging visualization [2] for example, inviting students to hold in mind Max's epic journey which paradoxically takes place before his soup even has a chance to cool down (Where The Wild Things Are, see Table 1)

- Dynamically representing important mathematical ideas [66], such as transformation and scale factor; for example, when watching Hector shrink the toilet to a fraction of its original size (Despicable Me; see Table 1)

More generally, it has been previously argued that learning mathematics through problem solving tasks that are augmented through enabling and extending prompts, such as the tasks in the current study, can promote student feelings of competence and mastery [67]. Enabling and extending prompts are tools to support differentiated learning experiences to allow all students to engage in optimally challenging problem solving [11]. According to Sullivan and colleagues [11,68,69], enabling prompts are designed to make the main task more accessible through strategies such as removing a step in the problem, changing the representation, simplifying the numbers, or connecting the problem to prior learning. Extending prompts expose students to an additional task that is more challenging, but requires students to use similar representations, reasoning and conceptualizations to the main task.

Table 1. Narrative-based challenging mathematical tasks included in the study.

\begin{tabular}{cl}
\hline \multicolumn{1}{c}{ Narrative (Medium) } & \multicolumn{1}{c}{ Mathematical Task } \\
\hline Despicable Me (movie clip) & How many times smaller is the tiny toilet than the regular toilet? \\
\hline Coin Operated (short film) & $\begin{array}{l}\text { Imagine one } 5 \mathrm{c} \text { coin propels his rocket } 50 \mathrm{~cm} \text {. Space is } 100 \mathrm{~km} \text { away. How } \\
\text { many 5c coins does the boy need in order to become a real astronaut who has } \\
\text { been to outer space? }\end{array}$ \\
\hline Where the Wild Things Are (picture story book) & $\begin{array}{l}\text { How much more quickly does time pass in the Land of the Wild Things } \\
\text { compared with the real world? }\end{array}$ \\
\hline We're Going on a Bear Hunt (picture story book) & $\begin{array}{l}\text { On the way back, the family went a lot quicker to avoid being eaten by the } \\
\text { bear, and they got back to their house in exactly an hour. If they travelled at } \\
\text { least twice as quickly through each obstacle on the way back, can you work out } \\
\text { how long it might have taken them to travel back through the grass, river, mud, } \\
\text { forest, snowstorm and cave? Can you find more than one possible set } \\
\text { of answers? }\end{array}$ \\
\hline
\end{tabular}

\subsubsection{Relatedness}

Relatedness reflects the need to connect with, and be accepted by, significant others. More generally, it involves feeling a sense of belonging to a social group [57]. Relatedness in a learning environment is supported by positive, mutually validating relationships with both one's peers and teachers. To further support relatedness, student choices in relation to a particular learning environment "must be congruent with the students' social relationships and culture" [60] (p. 259).

The importance of meeting students' need for relatedness when learning mathematics should not be understated. For instance, there is strong evidence that students value working collaboratively on mathematical tasks [8,70,71]. Moreover, when students require support with a mathematical task and both teachers and peers are available, students are three times more likely to seek help from peers, rather than their teacher [72]. In the context 
of our study, we would argue that the structure of these narrative-driven mathematics lessons would support students in meeting their need for relatedness in at least three ways:

- Through the shared social experience of listening to, and/or viewing, a culturally relevant narrative to launch a mathematics lesson;

- Through opportunities to work collaboratively with other students, after 10 minutes of exploring the task independently;

- Through participating in a post-task mathematical discussion structured around their peers' work on the task.

\section{Materials and Methods}

The current study was intended to be both exploratory and qualitative in nature, and aimed to examine the student experience of learning mathematics through rich problem solving tasks launched through narratives in the form of picture story books, short films and movie clips. Note that the focus of the current paper is on the learning experience from the student perspective. As such, how the tasks elicited the targeted mathematical thinking from a teacher perspective, in particular, how they supported students to reason proportionally, is beyond the scope of the current paper; however, this is discussed elsewhere (e.g., see [63]).

\subsection{Participants}

Participants in the current study were drawn from the 47 students from two Year (Grade) 5 classes attending a primary school located in the inner-north of Melbourne, Australia. In Melbourne, students typically turn 11 years old in Year 5. The school the students attended was comparatively socio-economically advantaged in terms of the parent communities' occupation and education levels. The school's Index of Community SocioEducational Advantage (ICSEA) was 1154, with 69\% of student families distributed in the top quartile of the Australian population on this measure.

Twenty-four of these 47 students who had returned parental consent and student ascent forms, and were available to participate in follow-up interviews on the day in which the researchers (first two authors) were in the school conducting the interviews, comprised the study participants. Twenty participants were present for all three lessons, two were present for two of the lessons, whilst two were only present for a single lesson.

\subsection{Procedure}

During Term 3 of 2019, the researchers (first two authors) taught three mathematics lessons to each of the two classes of Year 5 students. Each class participated in one lesson launched from a picture story book (either Where the Wild Things Are; [73] or We're Going on a Bear Hunt; [74]) one lesson launched from a two-minute clip from a movie (Despicable Me; [75]) and one lesson launched from a Pixar short film (Coin Operated; [76]). These specific narratives were chosen both because they were likely to be familiar to students and because each provided a context for a meaningful proportional reasoning problem solving task. Each of these lessons lasted approximately 50 to $60 \mathrm{~min}$ and followed the launchexplore-discuss/summarize structure frequently utilized when learning mathematics through problem solving $[68,77,78]$. For the Despicable Me lesson, we cycled through these three phases on two occasions. An adaptation to this lesson structure is noted elsewhere in the literature (e.g., see [79] and their instructional model incorporating (re)launch, re(explore), (re)summarize/review). Note that the core tasks used in each of the lessons are briefly summarized in Table 1, whilst the full tasks have been published elsewhere (Where the Wild Things Are, [80]; We're Going on a Bear Hunt, [81]; Despicable Me and Coin Operated, [63]).

Specifically, we launched each lesson by presenting the narrative to students (i.e., reading the picture story book, displaying the movie clip or screening the short film). We then invited students to summarize the key components of the story, put forward several provocative questions to further immerse students in the narrative world, and finally 
presented a mathematical task to students that we believed emerged authentically from the story. Elsewhere we have described this approach to launching a mathematics task as a narrative-first approach [17]. During the explore phase of the lesson, students spent the first five minutes working independently on the task. After this time, students who required further support accessed the enabling prompt. Approximately ten minutes into the explore phase, students were invited to collaborate with peers, which most students chose to do. Finally, the discuss/summarize phase of the lesson involved several specifically chosen students presenting their progress on the task. Our role as teachers was to highlight connections between different approaches, as well as connecting these approaches to the underlying mathematical focus.

On the day after the third lesson was completed, individual semi-structured interviews were undertaken with the 24 participants by the researchers (first two authors). All interviews were between four and eight minutes in duration (median time = five minutes). The interviews began with the researchers briefly recapping the three lessons and gesturing towards print outs of the three problems, with prompting visual images. Participants were reminded that one lesson was based on a clip from a movie (Despicable Me), one was based on a short film (Coin Operated), and one on a children's book (Where the Wild Things Are or We're Going on a Bear Hunt). Participants were asked how these lessons compared to their regular mathematics instruction, and the researchers probed around the ideas of enjoyment, learning and challenge. Participants were also asked which lesson they preferred and why, and what would be their preferred narrative medium for learning mathematics in the future (movie clips, short films, picture story books) and the reason(s) for this.

\subsection{Analysis}

Data were analyzed thematically [82]. Transcripts were read, reread and annotated, with salient characteristics being highlighted. Key information from each of the annotated transcripts was then summarized into a paragraph (approx. 100-150 words), distilling the responses of each of the interviewees into a consistently structured block of text. These summaries included: a note about the number of lessons students participated in; their overall reactions to the lesson; the reasons provided for these reactions; an indication of their favorite lesson; and their preferred mode of narrative learning. For example:

Maya participated in all lessons (including We're Going on a Bear Hunt). Overall, Maya found working on these contextualized problems more interesting, challenging and enjoyable than what she described as her usual mathematics lessons, which she indicated had a heavy emphasis on practice. She valued both the opportunities to make choices and the connection to real life. Her favorite lesson was the Coin Operated task, because she found the visual images compelling, had a clear sense of what the problem was getting at and worked on the problem independently. Interestingly, despite indicating she learnt better visually and despite nominating Coin Operated as her favorite lesson, she indicated a preference for picture story books as her preferred narrative medium for future mathematics lessons.

These summaries were then read and reread, and several key themes were extracted. The primary interview transcripts were then revisited with these themes in mind, with each transcript being systematically coded to respective key themes when relevant. As part of this process, specific text that connected to the relevant themes was highlighted, with the most clearly articulated and relevant quotes that illustrated a given theme set-aside for inclusion in our analysis. Finally, consideration was given to whether each theme could be connected back to the three psychological needs postulated in self-determination theory: autonomy, competence and relatedness; the theoretical framework underpinning the study. As none of the three themes that emerged initially could be connected directly to the need for relatedness, the interview transcripts were re-examined to see if any of the participant comments resonated with this particular psychological need, and whether an additional associated theme could be extracted from the data. 
In addition to this thematic analysis, participants were asked directly which of the narrative mediums they preferred when learning mathematics. These preferences are presented, with the various explanations students provided for these preferences noted.

\section{Results}

The lessons were almost universally acknowledged as challenging, with 23 out of the 24 students stating that the lessons were notably more challenging than mathematics as usual. Likewise, there was consensus amongst the students interviewed that the lessons were enjoyable compared with mathematics as usual. Although there was evidence that this enjoyment stemmed in part from the novelty of the learning experience, the argument presented in our theoretical framework is that the lessons would be perceived as enjoyable because they would meet students' three psychological needs for autonomy, competence and relatedness. Four key themes emerged from our final analysis, each of which can be connected to one of these three psychological needs.

\subsection{Autonomy: Rich and Familiar Contexts Made the Mathematics More Purposeful $(n=20)$}

Most students (83\%) emphasized during the interview that presenting a mathematical task through a narrative context made learning the mathematics seem more purposeful and relevant. We conceptualized this as students having their need for autonomy met as they worked on these tasks. The claim is that the familiar narratives allowed students to connect the mathematics to contexts that were personally meaningful to them, such as a well-loved picture story book or a popular movie. These fictional worlds are alive for students, as they feel psychologically close to these rich stories. In the language of self-determination theory, these lessons promoted students' sense of autonomy and engagement in the learning through supporting integrated regulation.

Several students suggested their usual mathematics classes lacked context, and therefore purpose, for their learning, in contrast to their experience of these narrativebased lessons:

I really like them because it sort of gives it a backbone. It gives it something to go off ... It kind of like gives it purpose. Because I mean, I think I'm one of those people who has to see the point to something. If it is just math, then it is not really that exciting, but if it's, say, a story behind it, it actually makes it more fun because you're actually doing something to do with the story as well. (Hermin)

It kind of interests' people a bit more, because it will spark something in their minds ... Because like it's a film, it gets them more interested in the topic. Normally you get bored because you don't even know why you're doing it. Just to solve the answers. But, say with the rocket, this is to figure out how much money he would need to go that far. (Reece)

These lessons were challenging and based on something unlike Mr X's classes which just were, ah, either practicing on Essential Assessments or things... I think it was really good because yesterday when we read, We're Going on a Bear Hunt it was really fun to read and the questions were related to the topic... It made it more interesting. (Maya)

In our regular math lessons, we get worksheets... (Having a story at the start of the lesson) was useful because it kind of gave you, like, a reason to do it, instead of just working out the math. (Nancy)

Several students noted that their personal familiarity and prior knowledge of these stories made the mathematics lesson more relatable:

I liked it because yeah, I was familiar with it ... it just made it a bit more relatable because I'd seen the movies and I knew what they were talking about. (Rachel)

I like it more. Because I know a lot of these things a bit more than what we normally would do ... It changed it because I knew what it was, not just starting from scratch doing something. I've read the Wild Things quite a lot and I've watched Despicable Me, and I've seen a lot of Pixar short films. (Charlie) 
I think it's good because, like, it was things you already knew about. And, like, you had past knowledge of it, well some people would have. That past knowledge made it fun. And usually math lessons are just like a piece of paper, here's multiplication, do stuff. It's not based off this. (Honey)

Building on this idea, there is a sense in which by working on a mathematical task that is embedded in the narrative students actually deepen their engagement with the narrative, as articulated by Shaun:

If we're doing like a worksheet, it would be something we don't really know about... but this was like we had all read the book and it kind of made sense to look into it. And it was fun to like, look at something that we had seen before and then look into it deeper and have a greater understanding about it.

\subsection{Autonomy: Open Tasks Support Student Choice $(n=9)$}

Our next theme confirms that many students (38\%) valued working on tasks where they could make choices about how they approached the mathematical work. In addition, students appreciated that some of the tasks had multiple viable answers, with the acceptability of a given answer depending on the quality of student reasoning. This again connects to supporting students to meet the psychological need for autonomy.

I enjoyed these much more because we could do things our way instead of getting, like, something, like a math sheet and having to do it this one way. (Ashleigh)

And there were so many ways you could do it. And it was hard as well. So, like, it was hard, but that's what made it fun. And like there were so many ways, like 'How do I do this? Do I add something on here or do I split this up?'. (Honey)

In all of them there was like some different ways you could work it out. Especially in this one, the Wild Things one, there was a lot of estimating which I kind of like because you can choose your own way.... (Nancy)

As noted by Jane, the openness of the problems enabled students to think more creatively, and break away from viewing mathematics as a set of routine tasks to complete:

There's lots of creativity involved. There's lots of options to go through ... In usual math there would be just sums in a row, they're all like generic. But this kind of adds a splash of color.

\subsection{Competence: The Narrative Presentation Supported Student Understanding $(n=16)$}

The next theme to be discussed is the notion that connecting the mathematical task to the narrative supported student understanding of the mathematical idea being explored. In terms of our self-determination theory lens, we connected this to the notion that these lessons met students' need for competence. Most students (67\%) indicated that the narrative structure supported their understanding in some capacity.

Some students noted that these lessons, although challenging, were in fact easier to follow than a regular mathematics class because of this narrative structure. It seems that the familiarity and sense of purpose (supporting autonomy) supported students to persist with more challenging mathematical work (supporting competence):

Sometimes [in a regular math lesson] you could do 'it takes this long to travel somewhere in a boat' but not with a story background like Where the Wild Things Are.... I could relate to the things, and I knew what was going on in them. (Leroy)

I really like them. They were a lot easier to follow ... Um, because we were doing it originally on something. In normal lessons we are just figuring out how to do one thing and turn it into another. (Walter)

Well, they were funner than the rest of them. Because you got to like go off things, movies and books and stuff. And it was kind of frustrating, but you wanted to get it so that's what made it fun. Like you wanted to keep trying. (Honey) 
One of the other ways in which launching the mathematics through the narratives supported student mathematical thinking was that it enabled students to focus on the related visual images and illustrations. Although students were not always able to clearly articulate how viewing these images assisted them in understanding the mathematics, it seems that in part they made abstract ideas more concrete and accessible.

And I think the video or book sometimes makes it a little easier to work out ... Like with the toilet one you could see it was as big as your hand. (Nancy)

You got to see the stuff that was happening instead of maybe being told. And then you got to like do an activity on it, like go back and look over it ... because you sort of have a picture of it ... I don't know, it just helps. (Eliza)

But I found this one a bit clearer than it [mathematics] usually is ... I don't know if it was visuals because you read the book to us but I just kind of got it. (Felicity)

Other students noted more specifically that the dynamic imagery (viewing the movie clip and short film) further supported their understanding, implying that the moving images served as a model for the mathematical idea.

I like the films so that you could see it virtually and what was going on. So you see, especially with the shrunken toilet one, you could kind of get the picture of how far it had shrunken... So you could like work it out a lot easier with the film. If you, like go back to see how much it had shrunken... I think the film is easiest because you can actually see it ... instead if you write it on the board, it could be a bit different to what actually has happened. (Cameron)

Because you kind of, like mainly with the videos, you can see it in your mind as well ... Well, I feel like when the questions come up in tests, like someone has this many cookies and they have to share it with an amount of people, I usually try to count in my mind, but I haven't seen the people. (Jonah)

Finally, it was also noted that the narrative presentation helped students to think back on the mathematical task, and made it easier to bring the problem to mind.

It did help with my learning [that it was connected to the story] because if I kind of get stuck I just remember the story and go on from that. (Di)

They were definitely better than regular math lessons ... because of the storyline, you know what you are thinking about. (Leroy)

It is kind of easier to understand what you need to do ... Because with the story you can always think back on it and ... you can remember it ... you just think of the video and you can just get the question in your head. (James)

\subsection{Relatedness: Students Valued Opportunities to Collaborate and Interact $(n=3)$}

Although we argued that the manner in which the mathematics lessons were structured supported students in meeting their need for relatedness, only three students explicitly noted that they valued opportunities for collaboration and interaction during the lesson.

Charlie found the opportunity to work with another student supported his learning, and was something he was not typically afforded in a regular mathematics class.

Well, it was quite hard to figure out what to do. I worked with someone sometimes. Most of the time. And we would do it together. [Did you find that collaboration helpful to your learning?] Yeah. [Is that how you normally work during math lessons?] Not really, no.

Rachel indicated she appreciated exchanging ideas with peers while working on problem solving tasks.

I found (We're Going on a) Bear Hunt a bit easier. It had a bit more of a structure because it said that it had to be under sixty minutes, and we could also work with other people. [So, you like to be able to work with other people?] Yeah, because we could share ideas. 
Finally, Felicity appreciated that the teachers orchestrating the lessons (i.e., the first two authors) interacted with the students, valued their thinking and support their autonomy.

Most lessons the teachers just say 'oh this is division, you need to do it like this, go off and do it.' Because you were kind of interacting with us instead ... you let us say our noticings and do things that we wouldn't normally do.

\subsection{Preference for a Specific Narrative Medium}

Participants were also asked during the interview if in the future, they would prefer narrative-based mathematics lessons to be launched from picture story books, clips from popular movies, or short films. Participant responses are aggregated in Table 2.

Table 2. Student preferences for narrative mediums to learn mathematics.

\begin{tabular}{lc}
\hline \multicolumn{1}{c}{ Narrative Medium } & $\begin{array}{c}\text { Number of Students } \\
\text { (Percentage of Responding Students) }\end{array}$ \\
\hline Picture Story Books & $6(27 \%)$ \\
Moving Picture & $10(45 \%)$ \\
$\quad$ Movie Clips & 4 \\
$\quad$ Short Films & 3 \\
$\quad$ Movie Clips or Short Films & 3 \\
No preference & $6(27 \%)$ \\
Total & 22 \\
\hline Note:
\end{tabular}

Note: Two students were not probed about their preferences during the interview.

There was an evenly distributed spread of student preferences for using the three narrative mediums to learn mathematics. Specifically, approximately equal numbers of students preferred movie clips $(n=7)$, short films $(n=6)$, picture story books $(n=6)$ or had no preference for a particular narrative medium $(n=6)$.

Students who preferred learning mathematics through the picture story book medium noted that, compared with the moving pictures, picture story books allowed students to absorb the narrative at their own pace. It was also suggested that picture story books demanded more focused attention and provided less opportunities to become distracted.

I think a book would be better because if you just do a video everybody would get, um, well most people would get caught up in the video and not really listen and think about. With the book you can actually look at the pictures for longer and read the words yourself. (Ashleigh)

Well, I think a book is probably more interesting because you probably have to be really focused with the pictures and illustrations more than a movie. In a movie you're just watching what everyone's doing. With a book you're actually like listening and kind of like seeing what the illustrations are. (Di)

Maybe books more. Because I don't really know, to me I just thought we could read it and look back over it and look at all the pages as well and go back to reference it. (Shaun)

By contrast, students who nominated either a clip from a movie or a short film emphasized that the moving images helped to make the lesson clearer and easier to follow, possibly because the experience was more immersive.

I'd probably choose clips of films ... Or maybe the short film one. I just feel like the video is more clear ... because they are kind of like actually moving and doing it. Where in a book it is kind of like just pictures. (Jonah)

I think a video because it's got a bit more visuals and it still has the sound. Videos are basic visuals, so you can see what's going on with it. In the book it was sometimes a bit hard to see because I was sitting so far back. So, like, because it was up on the big TV and we could all see it, and it kind of gave you the sounds of it. And I don't know why but the sounds kind of helped. (Nancy) 
Students who nominated movies specifically tended to emphasize that they found watching movies more enjoyable and entertaining.

I like watching movies and they're just fun to make it interesting. (Sid)

Students who nominated short films tended to emphasize the value of experiencing the complete story.

Maybe the entire short film because you've got the whole thing ... because I might have missed something in Despicable Me if I haven't watched it. And then I don't understand how they got that shrink ray ... it just helps it [the mathematics] a little bit to come together more and the answers work. (Eliza)

I like the short films. So, you can see, it's not really long, it's not like really slow 'Then he walks back to the house', it's like a speed run through a little story... You won't be sitting there for another ten minutes and like 'what happened at the start again?'. (Cameron)

This was particularly the case for students who were less familiar with popular movies.

I would do short films because with movies there's not a lot of them that I've seen. (James)

Indeed, familiarity with the narrative medium was an important reason nominated by several students, regardless of their preference.

[Preference for movies] because more people know the movies than the short films and the books. (Leroy)

[Preference for books] And also, I haven't watched any of that, but I, like, knew the book. (Zed)

[No preference] You would have read or seen them before. And then that would kind of give you a little help because you know what the movies about or the book. (Walter)

Students who had no preference for a particular narrative medium tended to emphasize that the value was in launching the lesson through a rich narrative, independent of the medium. This was exemplified by Hermin's comment:

It doesn't even have to be a movie or a book or anything. I like it if there's a story ... I personally like it to be a more elaborate story. Because just for me it makes it [the mathematics] lots more interesting....

\section{Discussion and Conclusions}

The first research question examined how students compared the experience of learning mathematics through challenging mathematical tasks launched from a narrative, compared with a typical mathematics lesson. All students enjoyed the lessons, whilst almost all found the mathematics considerably more demanding than regular classroom mathematics instruction. Moreover, all four themes that emerged through an analysis of the student interview data resonated with one of the three basic psychological needs articulated in self-determination theory: autonomy, competence and relatedness [58]; although the theme connected to relatedness ("Students valued opportunities to collaborate and interact") only emerged after an additional examination of the interview data.

As put forward in our theoretical framework, embedding mathematical tasks in rich, familiar narratives did indeed make the learning of mathematics more purposeful from the perspective of students, thus supporting student autonomy. It is striking that this connection between the current suite of lessons and more meaningful mathematics was made by most students (83\%), despite this issue not being directly probed for in student interviews. Autonomy was also supported by the structure of the mathematical tasks allowing for multiple solutions and/or multiple solution pathways, resonating with other studies that have examined the student experience of learning through challenging tasks supported by enabling and extending prompts [8]. Moreover, despite these mathematical tasks being challenging, students felt competent grappling with the mathematical ideas, which were made more tangible to students through their representation in the narrative. 
Again, the majority of students $(67 \%)$ connected these lessons to their sense of feeling competent, for example, noting that these tasks were clearer and more accessible than a typical mathematics lesson, despite this issue not being probed directly.

In contrast to the other two psychological needs, there was only limited evidence of the narrative-based lesson structure supporting the need for relatedness. Rather than assume that these lessons only met students need for relatedness in a limited capacity, it may instead be speculated that this need was met implicitly. For example, it seems that students did in fact value the shared social experience of being absorbed in a culturally relevant narrative to launch a mathematics lesson, as evidenced by their reflection that learning mathematics in this manner was more purposeful and enjoyable. However, they did not explicitly highlight the social relatedness dimension, which may in part reflect the relatively young age of the students involved (i.e., 10 and 11 year olds).

The second research question considered whether students had a preference for a particular medium when learning mathematics through a narrative. Overall, a diversity of student preferences was noted, perhaps suggesting that it would be prudent for teachers to consider using a range of mediums to contextualize mathematical tasks, rather than make assumptions about which medium students might prefer. This resonates with Clarke and Roche's [13] finding that student preferences for the types of mathematical tasks they engage with are eclectic.

The comparative advantage of moving images (i.e., movie clips and short films) for at least some of the students who reported preferring this medium is that it did indeed serve to dynamically represent the notion of transformation and scale [66], and also supported these students to visualize the associated mathematical problem [2]. We postulated that both these two mechanisms would be important for helping students to meet the psychological need for competence as they worked on a narrative-based, challenging mathematical task. By contrast, those students who preferred picture story books often noted that this medium allowed them to absorb the narrative at their own pace and was less distracting, perhaps indicating that working on tasks connected to picture story books were particularly effective in meeting the psychological need for autonomy for such students. However, our overall sense of evaluating the student interview data is that the differences in mediums had only a relatively marginal influence on the student learning experience, and that students perceived all three lessons to be enjoyable, challenging and distinct from their usual mathematics instruction. Consequently, we would suggest that educators and researchers focused on the benefits of teaching mathematics through picture story books (e.g., $[27,30])$ consider extending their definition of narrative to encompass other mediums, such as movie clips and short films.

\section{Limitations and Implications}

The usual caveats apply to a small-scale exploratory study that was undertaken in a single school with students across a single year level in terms of the limited generalizability of the findings. In addition, we acknowledge that the first two authors are experienced mathematics educators with some specialist knowledge in teaching mathematics through challenging tasks in general, and tasks involving rich narratives in particular, and consequently we cannot assume that generalist primary teachers would necessarily be able to seamlessly implement these tasks and related pedagogies in their own classrooms. However, we still believe that the findings have important implications for practice.

This study highlighted the impact of familiar, relatable narratives as an effective way to make the learning of mathematics more purposeful and engaging. There is an opportunity for mathematics teachers to leverage student familiarity and interest in a particular narrative as a means to further promote their sense of autonomy, as described through self-determination theory. Specifically, students could be first invited to share their own favorite narratives, including picture story books, short films and feature movies. Next, teachers, perhaps supported by mathematics leaders in their schools, could develop challenging tasks around these student-chosen narratives using a structure similar to that 
outlined in this paper and elaborated elsewhere, which we refer to as the 'narrative-first approach' [17]. The second author on this paper has in fact experimented with using narratives chosen by students in his own mathematics teaching, specifically using a narrative context from the movie Shrek (as requested by students) to launch a rich, mathematical investigation [83]. Anecdotally, this generated high levels of student engagement and deep mathematical thinking.

Tertiary institutions supporting the development of preservice teacher educators should emphasize pedagogical approaches to teaching mathematics that promote purposeful learning and a high level of engagement, and we would encourage the inclusion of problem solving tasks contextualized around meaningful narratives as outlined in this article as one such approach. This could include preservice teachers developing their own challenging tasks around familiar narrative contexts, as well as them subsequently teaching with these tasks in a practical classroom environment. This may help to address one notable barrier to teaching mathematics using narratives such as picture story books that has been noted in the literature; specifically, that some teachers lack the pedagogical knowledge, confidence and experience to feel comfortable teaching mathematics in this manner [29].

Finally, there is an opportunity for further research into the value of different narrative contexts for supporting student engagement in mathematical problem solving. In addition to the narrative mediums utilized in this study, it may be valuable to explore the use of personal narratives (i.e., connecting mathematical problems to a students' own life)—which may be generated by the teacher or the students themselves - or teacher narratives (i.e., a teacher providing a personal narrative to contextualize a problem). There is also an opportunity to explore the effectiveness of using various narrative forms to contextualize mathematical learning amongst different age groups of students, including early years students and middle secondary school students.

To conclude, the current study provides further evidence that the use of narratives in their various forms allows mathematics to be taught in an integrated and embedded manner. It is worth noting that such an instructional approach is highly consistent with what has been described as driving the STEM agenda, that is, to provide "learning experiences that prepare students for a future that relies on them being innovative problem solvers" [84] (p. 27).

Author Contributions: J.R. and T.R. were responsible for conceptualizing the paper, developing the methodology, teaching the lessons, and analyzing the data. J.R. wrote the theoretical framework, methodology and discussion/conclusions and T.R. the implications. A.R. undertook the literature review, helped with editing the paper and organized the paper for publication. All authors have read and agreed to the published version of the manuscript.

Funding: This research received no external funding.

Institutional Review Board Statement: The study was conducted according to the guidelines of the Declaration of Helsinki, and approved by the Institutional Review Board (or Ethics Committee) of Monash University (2019-21611-34962).

Informed Consent Statement: Informed consent was obtained from all subjects involved in the study.

Data Availability Statement: Data are available from the authors on request.

Conflicts of Interest: The authors declare no conflict of interest.

\section{References}

1. Anthony, G.; Walshaw, M. Effective Pedagogy in Mathematics; International Academy of Education: Belley, France, 2009.

2. National Council of Teachers of Mathematics (NCTM). Principles and Standards for School Mathematics; NCTM: Reston, VA, USA, 2000.

3. Swan, M. Mathematics Matters. Final Report; National Centre for Excellence in the Teaching of Mathematics: London, UK, 2008.

4. Stein, M.K.; Grover, B.W.; Henningsen, M. Building student capacity for mathematical thinking and reasoning: An analysis of mathematical tasks used in reform classrooms. Am. Educ. Res. J. 1996, 33, 455-488. [CrossRef] 
5. Sullivan, P.; Mornane, A. Exploring teachers' use of, and students' reactions to, challenging mathematics tasks. Math. Educ. Res. J. 2014, 26, 193-213. [CrossRef]

6. Russo, J.; Hopkins, S. Student reflections on learning with challenging tasks: 'I think the worksheets were just for practice and the challenges were for maths'. Math. Educ. Res. J. 2017, 29, 283-311. [CrossRef]

7. Hiebert, J.; Grouws, D.A. The effects of classroom mathematics teaching on students' learning. In Second Handbook of Research on Mathematics Teaching and Learning; Lester, F.K., Ed.; Information Age Publishers: Charlotte, NC, USA, 2007; pp. 371-404.

8. Russo, J.; Minas, M. Student attitudes towards learning mathematics through challenging, problem solving tasks: It's so hard in a good way. Int. Electron. J. Elem. Educ. 2020, 13, 215-225. [CrossRef]

9. Wilkie, K.J.; Sullivan, P. Exploring intrinsic and extrinsic motivational aspects of middle school students' aspirations for their mathematics learning. Educ. Stud. Math. 2018, 97, 235-254. [CrossRef]

10. Russo, J.; McCosh, J.; Hewish, T. Students' attitudes towards learning mathematics through problem solving: I feel good because I make my head sore. Aust. Prim. Math. Classr. 2021, 26, 13-19.

11. Sullivan, P.; Mousley, J.; Jorgensen, R. Tasks and pedagogies that facilitate mathematical problem solving. In Mathematical Problem Solving; Kaur, B., Ed.; World Scientific Publishing: Singapore; Association of Mathematics Educators: Singapore, 2009 ; pp. 17-42.

12. Cai, J. What research tells us about teaching mathematics through problem solving. In Teaching Mathematics through Problem Solving; Lester, F.K., Charles, R.I., Eds.; National Council of Teachers of Mathematics: Reston, VA, USA, 2003; pp. $241-253$.

13. Clarke, D.; Roche, A. Using contextualized tasks to engage students in meaningful and worthwhile mathematics learning. J. Math. Behav. 2018, 51, 95-108. [CrossRef]

14. Borasi, R. On the nature of problems. Educ. Stud. Math. 1986, 17, 125-141. [CrossRef]

15. Yoon, C.; Chin, S.L.; Moala, J.G.; Choy, B.H. Entering into dialogue about the mathematical value of contextual mathematising tasks. Math. Educ. Res. J. 2018, 30, 21-37. [CrossRef]

16. Meyer, M.; Dekker, T.; Querelle, N.; Reys, R. Innovation in curriculum: Contexts in mathematics curricula. Math. Teach. Middle Sch. 2001, 6, 522-527. [CrossRef]

17. Russo, T.; Russo, J. Narrative-first approach: Teaching mathematics through picture story books. Aust. Prim. Math. Classr. 2018, 23, 8-15.

18. Lamon, S.J. Teaching Fractions and Ratios for Understanding: Essential Content Knowledge and Instructional Strategies for Teachers, 2nd ed.; Lawrence Erlbaum: Mahwah, NJ, USA, 2006.

19. Lesh, R.; Post, T.; Behr, M. Proportional reasoning. In Number Concepts and Operations in the Middle Grades; Hiebert, J., Behr, M., Eds.; NCTM: Reston, VA, USA, 1988; pp. 93-118.

20. Hilton, A.; Hilton, G.; Dole, S.; Goos, M.; O’Brien, M. Evaluating Middle Years Students' Proportional Reasoning. In Mathematics Education: Expanding Horizons, Proceedings of the 35th Annual Conference of the Mathematics Education Research Group of Australasia, Singapore, 2-6 July 2012; Dindyal, J., Chen, L., Ng, S., Eds.; MERGA: Singapore, 2-6 July 2012; pp. 330-337.

21. Staples, M.E.; Truxaw, M.P. An initial framework for the language of higher-order thinking mathematics practices. Math. Ed. Res. J. 2012, 24, 257-281. [CrossRef]

22. Bruner, J.S. The narrative construction of reality. Crit. Inq. 1991, 18, 1-21. [CrossRef]

23. Scholes, R. Language, narrative, and anti-narrative. In On Narrative; Mitchell, W.J.T., Ed.; University of Chicago Press: Chicago, IL, USA, 1981; pp. 200-208.

24. Chao, T.; Chen, J.; Star, J.R.; Dede, C. Using digital resources for motivation and engagement in learning mathematics: Reflections from teachers and students. Dig. Exp. Math. Educ. 2016, 2, 253-277. [CrossRef]

25. Sinclair, N.; Healy, L.; Sales, C. Time for telling stories: Narrative thinking with dynamic geometry. ZDM Int. J. Math. Educ. 2009, 41, 441-452. [CrossRef]

26. Colucci-Gray, L.; Burnard, P.; Cooke, C.; Davies, R.; Gray, D.; Trowsdale, J. BERA Research Commission Report: Reviewing the Potential and Challenges of Developing STEAM Education through Creative Pedagogies for 21st Century Learning: How Can School Curricula Be Broadened towards a More Responsive, Dynamic and Inclusive Form of Education? British Educational Research Association: London, UK, 2017.

27. Trakulphadetkrai, N.V.; Aerila, J.A.; Yrjänäinen, S. Bringing mathematics alive through stories. In Story in Children's Lives: Contributions of the Narrative Mode to Early Childhood Development, Literacy, and Learning; Kerry-Moran, K., Aerila, J.A., Eds.; Springer: Cham, Switzerland, 2019; Volume 16, pp. 199-226. [CrossRef]

28. Flevares, L.M.; Schiff, J.R. Learning mathematics in two dimensions: A review and look ahead at teaching and learning early childhood mathematics with children's literature. Front. Psychol. 2014, 5, 1-12. [CrossRef]

29. Livy, S.; Muir, T.; Trakulphadetkrai, N.V.; Larkin, K. Australian primary teachers perceived barriers to and enablers for the integration of children's literature in mathematics teaching and learning. J. Math. Teach. Educ. 2021. [CrossRef]

30. Muir, T.; Livy, S.; Bragg, L.; Clark, J.; Wells, J.; Attard, C. Engaging with Mathematics through Picture Books; Teaching Solutions: Albert Park, VIC, Australia, 2017.

31. Schiro, M. Integrating Children's Literature and Mathematics in the Classroom: Children as Meaning Makers, Problem Solvers, and Literary Critics; Teachers College Press: New York, NY, USA, 1997.

32. Clarke, D. Making measurement come alive with a children's storybook. Aust. Prim. Math. Classr. 2002, 7, 9-13.

33. Jenner, D.M. Experiencing and understanding mathematics in the midst of a story. Teach. Child. Math. 2002, 9, 167-171. [CrossRef]

34. Moyer, P.S. Communicating mathematically: Children's literature as a natural connection. Read. Teach. 2000, 54, $246-255$. 
35. Van den Heuval-Panhuizen, M.; Van den Boogaard, S.; Doig, B. Picture books stimulate the learning of mathematics. Aust. J. Early Child. 2009, 34, 30-39. [CrossRef]

36. Usnick, V.; McCarthy, J. Turning adolescents onto mathematics through literature. Middle Sch. J. 1998, 29, 50-54. [CrossRef]

37. Furner, J.M. Using children's literature to teach mathematics: An effective vehicle in a stem world. Eur. J. STEM Educ. 2018, 3, 1-12. [CrossRef]

38. Edelman, J.; Green, K.B.; Jett, C.C. Children's literature to inform mathematics teaching and learning: A systematic review of the research literature from 1991-2016. Int. J. Sci. Math. Technol. Learn. 2019, 26, 49-60. [CrossRef]

39. Hong, H. Effects of mathematics learning through children's literature on math achievement, and dispositional outcomes. Early Child. Res. Quart. 1996, 11, 477-494. [CrossRef]

40. Jennings, C.M.; Jennings, J.; Richey, J.; Dixon-Krauss, L. Increasing interest and achievement in mathematics through children's literature. Early Child. Res. Quart. 1992, 7, 263-276. [CrossRef]

41. McAndrew, E.M.; Morris, W.L.; Fennell, F.S. Geometry-related children's literature improves the geometry achievement and attitudes of second-grade students. Sch. Sci. Math. 2017, 117, 34-51. [CrossRef]

42. Van den Heuval-Panhuizen, M.; van den Boogaard, S. Picture books as an impetus for kindergartners' mathematical thinking. Math. Think. Learn. 2008, 10, 341-373. [CrossRef]

43. Young-Loveridge, J.M. Effects on early numeracy of a program using number books and games. Early Child. Res. Quart. 2004, 19, 82-98. [CrossRef]

44. Capraro, R.M.; Capraro, M.M. Are you really going to read us a story? Learning geometry through children's mathematics literature. Read. Psychol. 2006, 27, 21-36. [CrossRef]

45. Martinovic, D.; Freiman, V.; Karadag, Z. Visual mathematics and cyberlearning in view of affordance and activity theory. In Mathematics Education in the Digital Era; Martinovic, D., Frieman, V., Eds.; Springer: Dordrecht, Germany, 2013 ; pp. $209-238$. [CrossRef]

46. Pierce, R.; Stacey, K.; Ball, L. Mathematics from still and moving images. Aust. Math. Teach. 2005, 61, $26-31$.

47. Fielding-Wells, J.; Makar, K. Student (dis)engagement in mathematics. In Proceedings of the Annual Conference of the Australian Association for Research in Education, Brisbane, Australia, 30 November-4 December 2008. Available online: http:/ / www.aare. edu.au/08pap/mak08723.pdf (accessed on 15 March 2021).

48. Finn, J.D.; Zimmer, K.S. Student engagement: What is it? Why does it matter? In Handbook of Research on Student Engagement; Christenson, S.L., Reschly, A.L., Wylie, C., Eds.; Springer: New York, NY, USA, 2012; pp. 97-131.

49. Skinner, E. Engagement and disaffection as central to processes of motivational resilience and development. In Handbook of Motivation at School, 2nd ed.; Wentzel, K.R., Miel, D.B., Eds.; Routledge: New York, NY, USA, 2016; pp. 145-168.

50. Fredricks, J.A.; Blumenfeld, P.C.; Paris, A.H. School engagement: Potential of the concept, state of the evidence. Rev. Educ. Res. 2004, 74, 59-109. [CrossRef]

51. Marks, H.M. Student engagement in instructional activity: Patterns in the elementary, middle, and high school years. Am. Educ. Res. J. 2000, 37, 153-184. [CrossRef]

52. Renninger, K.A. Individual interest and its implications for understanding intrinsic motivation. In Intrinsic and Extrinsic Motivation: The Search for Optimal Motivation and Performance; Sansone, C., Harackiewicz, J.M., Eds.; Academic: New York, NY, USA, 2000; pp. 375-407.

53. Renninger, K.A.; Hidi, S. The Power of Interest for Motivation and Engagement; Routledge: New York, NY, USA, 2015.

54. Ainley, M. Students' interest and engagement in classroom activities. In Handbook of Research on Student Engagement; Christenson, S.L., Reschly, A.L., Wylie, C., Eds.; Springer: New York, NY, USA, 2012; pp. 283-302.

55. Middleton, J.A. More than motivation: The combined effects of critical motivational variables on middle school mathematics achievement. Middle Grades Res. J. 2013, 8, 77-95.

56. Schukajlow, S.; Krug, A. Do multiple solutions matter? Prompting multiple solutions, interest, competence, and autonomy. J. Res. Math. Educ. 2014, 45, 497-533. [CrossRef]

57. Krapp, A. Basic needs and the development of interest and intrinsic motivational orientations. Learn. Instr. 2005, 15, 381-395 [CrossRef]

58. Deci, E.L.; Ryan, R.M. Self-determination theory. In Handbook of Theories of Social Psychology; Van Lange, P.A.M., Kruglanski, A.W., Higgins, E.T., Eds.; Sage: Thousand Oaks, CA, USA, 2012; Volume 1, pp. 416-433. [CrossRef]

59. Ryan, R.M.; Deci, E.L. Self-Determination Theory: Basic Psychological Needs in Motivation, Development, and Wellness; Guilford Publications: New York, NY, USA, 2017. [CrossRef]

60. Kaplan, A.; Patrick, H. Learning environments and motivation. In Handbook of Motivation at School, 2nd ed.; Wentzel, K.R., Miel, D.B., Eds.; Routledge: New York, NY, USA, 2016; pp. 251-274.

61. Niemiec, C.P.; Ryan, R.M. Autonomy, competence, and relatedness in the classroom: Applying self-determination theory to educational practice. Theor. Res. Educ. 2009, 7, 133-144. [CrossRef]

62. Ryan, R.M.; Deci, E.L. Intrinsic and extrinsic motivations: Classic definitions and new directions. Contemp. Educ. Psychol. 2000, 25, 54-67. [CrossRef]

63. Russo, J.; Russo, T. Movies through a mathematical lens. Aust. Prim. Math. Classr. 2020, 25, $20-26$. 
64. Deci, E.L. The relation of interest to motivation and human needs-The self-determination theory viewpoint. In Interest and Learning: Proceedings of the Seeon Conference on Interest and Gender; Hoffman, L., Krapp, A., Renninger, K., Baumert, J., Eds.; IPN: Kiel, Germany, 1998; pp. 146-163.

65. Reeve, J. A self-determination theory perspective on student engagement. In Handbook of Research on Student Engagement; Christenson, S.L., Reschly, A.L., Wylie, C., Eds.; Springer: New York, NY, USA, 2012; pp. 149-172.

66. Bell, L.; Juersivich, N.; Hammond, T.C.; Bell, R.L. The TPACK of Dynamic Representations. In Educational Technology, Teacher Knowledge, and Classroom Impact; Ronau, R., Rakes, C., Niess, M., Eds.; IGI Global: Hershey, PA, USA, $2012 ;$ pp. $103-135$.

67. Russo, J.; Minas, M.; Hewish, T.; McCosh, J. Using prompts to empower learners: Exploring primary students' attitudes towards enabling prompts when learning mathematics through problem solving. Math. Teach. Educ. Dev. 2020, $22,48-67$.

68. Sullivan, P.; Askew, M.; Cheeseman, J.; Clarke, D.; Mornane, A.; Roche, A.; Walker, N. Supporting teachers in structuring mathematics lessons involving challenging tasks. J. Math. Teach. Educ. 2015, 18, 123-140. [CrossRef]

69. Sullivan, P.; Bobis, J.; Downton, A.; Hughes, S.; Livy, S.; McCormick, M.; Russo, J. Ways that relentless consistency and task variation contribute to teacher and student mathematics learning. In For the Learning of Mathematics Monograph 1: Proceedings of a Symposium on Learning in Honour of Laurinda Brown; Coles, A., Ed.; FLM Publishing Association: New Westminster, BC, Canada, 2020; pp. 32-37.

70. Calder, N.; Jafri, M.; Guo, L. Mathematics education students' experiences during lockdown: Managing collaboration in eLearning. Educ. Sci. 2021, 11, 191. [CrossRef]

71. César, M.; Santos, N. From exclusion to inclusion: Collaborative work contributions to more inclusive learning settings. Eur. J. Psychol. Educ. 2006, 21, 333-346. [CrossRef]

72. Araya, R.; Gormaz, R. Revealed preferences of fourth graders when requesting face-to-face help while doing math exercises online. Educ. Sci. 2021, 11, 429. [CrossRef]

73. Sendak, M. Where the Wild Things Are; Harper \& Row: New York, NY, USA, 1963.

74. Rosen, M. We're Going on a Bear Hunt; Walker Books: London, UK, 1989.

75. Meledandri, C.; Cohen, J.; Healy, J.; Coffin, P.; Renaud, C. Despicable Me [Motion Picture]; Universal Pictures: New York, NY, USA, 2010.

76. Dalman, J.; Arioli, N. Coin Operated [Animated Short Film]; Universal Pictures: New York, NY, USA, 2017.

77. Lappan, G.; Fey, T.; Fitzgerald, W.M.; Friel, S.; Phillips, E.D. Connected Mathematics 2: Implementing and Teaching Guide; Pearson Prentice Hall: Boston, MA, USA, 2006.

78. Stein, M.K.; Engle, R.A.; Smith, M.S.; Hughes, E.K. Orchestrating productive mathematical discussions: Five practices for helping teachers move beyond show and tell. Math. Think. Learn. 2008, 10, 313-340. [CrossRef]

79. Sullivan, P.; Bobis, J.; Downton, A.; Feng, M.; Hughes, S.; Livy, S.; Russo, J. An instructional model to support planning and teaching student centred structured inquiry lessons. Aust. Prim. Math. Classr. 2021, 26, 9-12.

80. Russo, T. Challenging task: Where the wild things are. Prime Number 2018, 33, 16-19.

81. Russo, J.; Russo, T. Investigations: Bear hunt. Prime Number 2021, 36, 24. Available online: https://www.researchgate.net/ publication/353265019_Investigation_We\%27re_Going_on_a_Bear_Hunt (accessed on 20 August 2021).

82. Braun, V.; Clarke, V. Using thematic analysis in psychology. Qual. Res. Psychol. 2006, 3, 77-101. [CrossRef]

83. Russo, T.; Russo, J. Investigations: Shrek. Prime Number 2021, 36, 24.

84. Anderson, J.; English, L.; Fitzallen, N.; Symons, D. The contribution of mathematics education researchers to the current STEM education agenda. In Research in Mathematics Education in Australasia, 2016-2019; Way, J., Attard, C., Anderson, J., Bobis, J., McMaster, H., Cartwright, K., Eds.; Springer: Singapore, 2020; pp. 27-57. 